Research Paper

\title{
A Phase II Randomized Controlled Trial: Definitive Concurrent Chemoradiotherapy with Docetaxel Plus Cisplatin versus 5-Fluorouracil plus Cisplatin in Patients with Oesophageal Squamous Cell Carcinoma
}

Yujia Zhu1,2*, Wenwen Zhang1,2*, Qiaoqiao Li1,2*, Qiwen $\mathrm{Li}^{11}{ }^{1,2}$, Bo Qiu1, 2, Hui Liu ${ }^{1,2}$, Mengzhong Liu ${ }^{1,2}$, Yonghong $\mathrm{Hu}^{1,2 \bowtie}$

1. Department of Radiation Oncology, Sun Yat-sen University Cancer Center, State Key Laboratory of Oncology in Southern China, Collaborative Innovation Center for Cancer Medicine, People's Republic of China;

2. Guangdong Esophogeal Cancer Research Institute, Guangzhou, Guangdong, People's Republic of China.

* These authors contributed equally to this work.

$\square$ Corresponding author: Yonghong Hu, MD, Department of Radiation Oncology, Sun Yat-sen University Cancer Center, 651 Dongfeng East Road, Guangzhou, Guangdong 510060, P.R. China. Tel.: +86-20-87343385; fax: +86-20-87343392; E-mail: huyh@sysucc.org.cn.

(c) Ivyspring International Publisher. This is an open access article distributed under the terms of the Creative Commons Attribution (CC BY-NC) license (https://creativecommons.org/licenses/by-nc/4.0/). See http://ivyspring.com/terms for full terms and conditions.

Received: 2017.03.13; Accepted: 2017.08.06; Published: 2017.10.10

\begin{abstract}
Purpose: To evaluate the efficacy and toxicity of definitive concurrent chemoradiotherapy (CCRT) with docetaxel plus cisplatin (DP regimen) versus 5-fluorouracil plus cisplatin (PF regimen) in patients with oesophageal squamous cell carcinoma (ESCC). Patients and Methods: In this phase II randomized controlled trial, eighty-six patients with clinical stage II - IVa ESCC were randomized to receive radiotherapy concurrently with two cycles of the PF or DP regimen at 3-week intervals. The primary endpoint was overall survival (OS). The secondary end points included the overall response rate (ORR), progression-free survival (PFS) and treatment-related toxicities. Results: The ORRs were $84.4 \%$ in the DP group and $87.3 \%$ in the PF group $(P=0.653)$. After a median follow-up time of 25.1 months, the 1 and 2 -year OS rates were $93.7 \%$ and $86.2 \%$ for the PF group and $87.3 \%$ and $69.1 \%$ for the DP group, respectively $(P=0.364)$. The 1 - and 2 -year PFS rates were $77.4 \%$ and $55.0 \%$ for the PF group and $78.8 \%$ and $69.4 \%$ for the DP group, respectively $(P=0.845)$. Grade $3 / 4$ leukocytopenia/neutropenia $(68.9 \%$ vs. $19.5 \%, P<0.001)$ was significantly more common in the DP group. Conclusion: The treatment response, OS and PFS associated with using CCRT with the DP regimen were not superior to those associated with using CCRT with the PF regimen as a first-line treatment in patients with ESCC. Additionally, the $\mathrm{DP}$ regimen was associated with more severe haematological toxicities. This trial has been registered with the US National Institute of Health (clinicaltrials.gov, Identifier NCT 02969473).
\end{abstract}

Key words: oesophageal cancer, chemotherapy, radiotherapy, oesophagus.

\section{Introduction}

Oesophageal cancer is one of the most fatal malignancies worldwide. It was estimated that 455,800 new cases and 400,200 deaths occurred worldwide in 2012 1. Radical surgery is the primary treatment for patients with resectable oesophageal cancer. For medically unfit patients or medically fit patients who decline surgery, definitive radiotherapy plus concurrent chemotherapy (CCRT) has been established as a standard treatment ${ }^{2-6}$. Since the 1980 's, the most widely used chemotherapeutic regimen in combination with radiotherapy for oesophageal cancer was cisplatin (CDDP) plus 5-fluorouracil (5-FU) (the PF regimen) ${ }^{4-7}$. However, locoregionally persistent or recurrent disease remained common, with poor survival. Several previous studies conducted by the radiation therapy 
oncology group (RTOG) have explored the efficacy of radiation dose escalation, but all results were disappointing 4, 8, 9. Studies incorporating intensified PF regimens or new-generation cytotoxic agents, such as paclitaxel and oxaliplatin, did not reveal any advantage over the standard-dosage PF regimen 2, 9, 10 .

Docetaxel is a semi-synthetic taxane that has exhibited radiation-sensitizing effects in vitro in several studies 11, 12. Studies have also reported promising results for docetaxel plus cisplatin (the DP regimen) in oesophageal cancer ${ }^{13-16}$. However, to date, no randomized phase III trial has been reported comparing the efficacy and safety of the DP regimen versus with the efficacy and safety of the PF regimen concurrent with radiotherapy in oesophageal cancer. In this phase II prospective randomized study, we compared the efficacy and toxicity between DP and $\mathrm{PF}$ regimens with CCRT in patients with oesophageal squamous cell carcinoma (ESCC).

\section{Patients and Methods}

\section{Eligibility criteria}

Inclusion criteria were as follows: (1) untreated patients with histologically proven squamous cell carcinoma of the oesophagus; (2) stage II to IVA disease, including metastatic celiac or cervical nodes, according to the $6^{\text {th }}$ edition of the American Joint Committee on Cancer (AJCC) staging system for oesophageal cancer; (3) aged between 18 and 70 years; (4) Karnofsky performance status (KPS) score $\geq 70$; (5) adequate bone marrow function (leukocyte count $\geq$ $4,000 / \mathrm{uL}$, platelet count $\geq 100,000 / \mathrm{uL}$ ), adequate liver function (serum alanine aminotransferase (ALT) level and serum aspartate aminotransferase (AST) level < twice the upper limit of normal, and serum bilirubin level of $<1.5 \mathrm{mg} / \mathrm{dL}$ ), and adequate renal function (creatinine clearance $\geq 50 \mathrm{~mL} / \mathrm{min}$ ); (6) no other serious medical conditions; (7) life expectancy $\geq 3$ months; and (8) written informed consent. Exclusion criteria were as follows: (1) detection of distant metastasis (excluding metastatic celiac or cervical nodes) before treatment; (2) known allergy to CDDP, $5-\mathrm{FU}$, or docetaxel; and (3) pregnancy or breast feeding.

\section{Baseline evaluations}

Baseline evaluation included a complete medical history and physical examination, complete blood count and serum chemistry profile, urinalysis, electrocardiogram, pulmonary function test, barium-swallow examination, contrast-enhanced computed tomography (CT) scan of the neck, chest and upper abdomen, and endoscopic ultrasonography. Bronchoscopy was performed if bronchial invasion was suspected. If clinically indicated, radionuclide bone scans and coregistered ${ }^{18} \mathrm{~F}$-labeled fluoro-2-deoxy-D-glucose positron emission tomography (PET) /CT scans were also performed.

\section{Design and random assignment}

This study was designed as a prospective, mono-centre, randomized phase II trial. This study was conducted at Sun Yat-sen University Cancer Center (SYSUCC) from October 2010 to March 2015. Eligible patients were randomized into the PF or DF groups at a 1:1 ratio, using a computerized randomization program. The ethics committee at SYSUCC reviewed and approved the protocol. Written informed consent was obtained from all patients or their surrogates. This trial has been registered with the US National Institute of Health (clinicaltrials.gov, Identifier NCT 02969473).

\section{Treatment}

The treatment schedule is outlined in Figure 1.

\section{Radiotherapy}

A cradle for immobilization was created with a vacuum with the patient in the supine position. A CT scan was performed with 5-mm-thick slices. The patient was scanned from the atlas (C1) to the second lumbar vertebra (L2) to cover the entire neck, oesophagus, lung and celiac lymph node regions. The gross tumour volume (GTV) included the macroscopic tumour and lymph nodes as shown by CT, PET/CT, endoscopy or endoscopic ultrasonography. Lymph nodes that exhibited at least one of the following features on CT were defined as positive lymph nodes: short axis $\geq 10 \mathrm{~mm}$, distribution in a cluster of lymph nodes, central necrosis or infiltrating margin. Lymph nodes that exhibited malignant signs on endoscopic ultrasonography or demonstrated uptake on the PET/CT scan were also included in the GTV regardless of the size. The clinical target volume (CTV) included the primary tumour plus a $3-\mathrm{cm}$ craniocaudal margin and a $1.0-\mathrm{cm}$ margin in other directions as well as the metastatic lymph nodes plus a 1-cm margin. Regional lymphatic drainages were also covered by the CTV, including the para-oesophagus and medial and upper mediastinal lymph nodes. The supraclavicular lymph node region was included when the primary tumour was located in the cervical or the upper thoracic oesophagus. For patients with lower thoracic oesophageal carcinoma, the paracardial lymph node region was also included in the CTV. The planning target volume (PTV1) included the GTV with a 5-mm margin in all directions, and the PTV2 generally included the CTV with a 5-mm margin in all directions. All patients 
underwent conventional radiotherapy at 1.8 to $2.0 \mathrm{~Gy}$ per fraction and 5 fractions per week. The prescribed dose was 60 to 64 Gy for PTV1 and 50 Gy for PTV2. Dose constraints for critical organs included the following: the maximal dose to the spinal cord was limited to $50 \mathrm{~Gy}$; the volumes of the lung receiving 20 Gy and 30 Gy were limited to $35 \%$ and $25 \%$; the volume of the heart receiving 45 Gy was limited to $50 \%$; and no more than $80 \%$ of the trachea could receive $>60$ Gy. Patients received either three-dimensional conformal radiotherapy (3D-CRT) or intensity-modulated radiation therapy (IMRT). Briefly, 3D-CRT treatment plans were calculated with the Pinnacle planning system (Pinnacle3 version $8.0 \mathrm{~m}$; Philips Medical Systems, Fitchburg, WI, USA), and IMRT treatment plans were calculated with the Monacle planning system (Monacle version 5.11, ELEKTA, US). All patients were treated with a 6-MV or 8-MV linear accelerator.

\section{Chemotherapy}

All patients received two cycles of chemotherapy concurrently with radiotherapy. As shown in Figure 1 , patients assigned to the DP group received two cycles of the DP regimen (docetaxel $60 \mathrm{mg} / \mathrm{m}^{2}$ delivered on day 1 and cisplatin $80 \mathrm{mg} / \mathrm{m}^{2}$ delivered on day 1) at a 3-week interval. Patients assigned to the $\mathrm{PF}$ group received two cycles of the PF regimen (cisplatin $80 \mathrm{mg} / \mathrm{m}^{2}$ delivered on day 1 and 5-FU $1,000 \mathrm{mg} / \mathrm{m}^{2}$ continuous infusion over 24 hours daily on days 1-4) at a 3-week interval. In cases of grade 4 haematological toxicity or severe non-haematological toxicities, dose adjustment was performed in the subsequent chemotherapy cycle.

\section{Assessment of treatment outcome and toxicity}

During treatment, complete blood counts and serum chemistry profiles were repeated every week, and barium-swallow examination was repeated every two weeks. After treatment, patients were followed for the first time during the $5^{\text {th }}$ or $6^{\text {th }}$ week after the end of treatment and every three months up to two years thereafter. Afterwards, follow-up was planned every six months up to five years or when clinically indicated. Medical history, physical examination, barium-swallow examination, and contrast-enhanced CT scan of the neck, chest and upper abdomen were performed at each follow-up visit. Endoscopy, brain magnetic resonance imaging (MRI), radionuclide bone scanning and PET/CT depended on the discretion of the treating physicians.

Treatment response was evaluated according to the criteria of Response Evaluation Criteria in Solid Tumors version 1.1 (RECIST 1.1). A senior radiologist together with a radiation oncologist evaluated the response approximately five to six weeks after the completion of treatment. Overall survival (OS) was defined as the time from randomization to death of any cause or the last follow-up. Progression-free

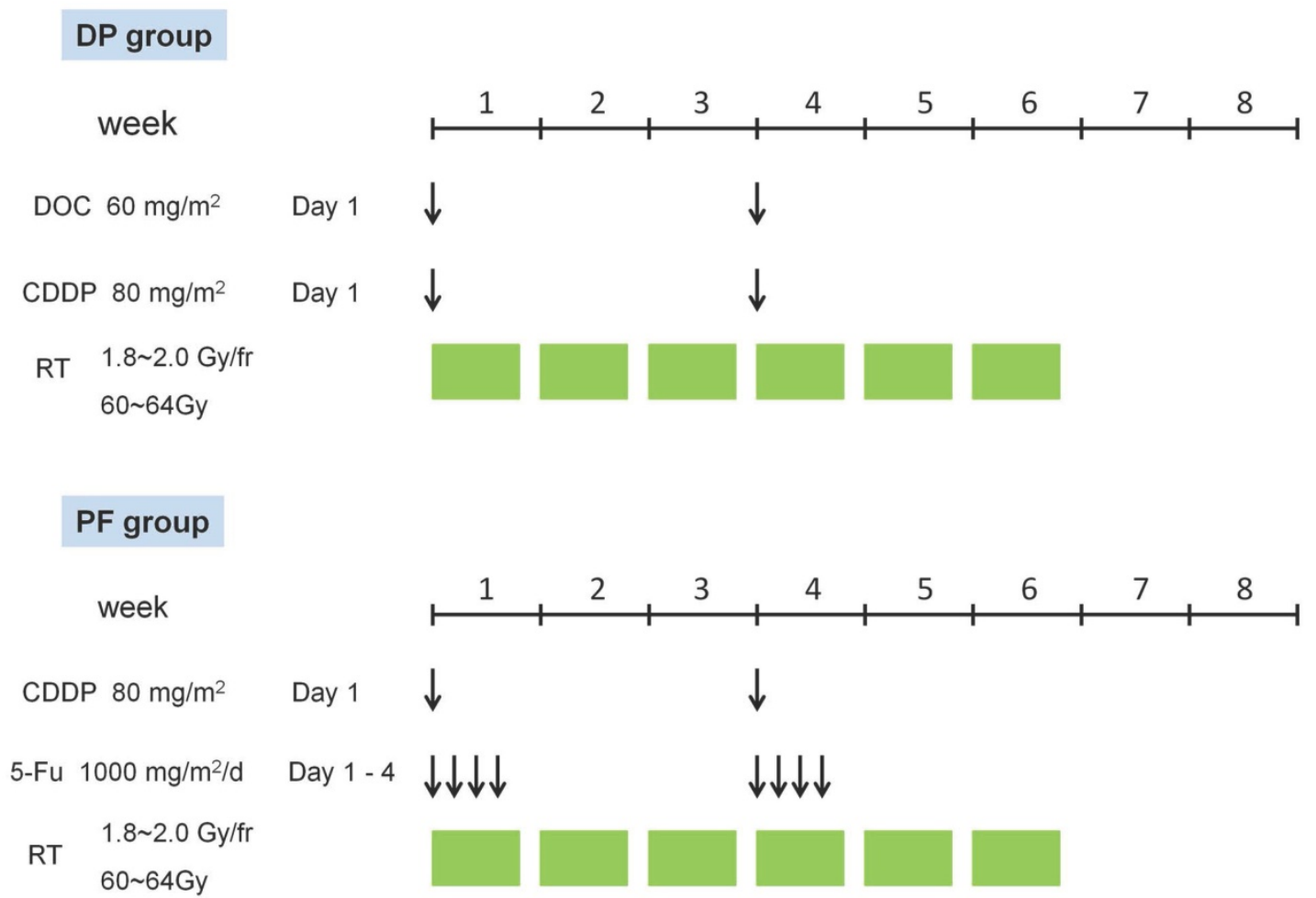

Figure 1. Treatment schedule of concurrent chemoradiotherapy in the DP group and the PF group. CDDP, cisplatin; DOC, docetaxel; DP, docetaxel plus cisplatin; fr, fraction; PF, cisplatin plus 5-FU. 
survival (PFS) was defined as the time from randomization to progression, relapse, death of any cause, or the last follow-up. Patterns of failure were defined according to the site of first treatment failure. Locoregional failure was defined as disease progression or relapse at the sites of primary tumour and/or regional lymph nodes. Distant failure was defined as disease progression or relapse at any site beyond the primary tumour and regional lymph nodes. Acute treatment-related toxicity was evaluated within six months from the beginning of treatment according to the Common Terminology Criteria for Adverse Events (CTCAE) version 3.0.

\section{Endpoints}

The primary endpoint of this study was OS. Secondary end points included the treatment response rate, PFS, patterns of failure, completion rate of the protocol, and treatment-related toxicities.

\section{Statistical analysis}

We used the Power and Sample Size Calculations software (Version 3.0, 2009, USA) to calculate the sample size. Prior data indicate that the median survival time on the control treatment is about 20 months. If the true median survival times on the control and experimental treatments are 20 and 35 months, respectively, we would need to study 91 experimental subjects and 91 control subjects to be able to reject the null hypothesis that the experimental and control survival curves are equal with probability (power) 0.900 . The Type I error probability associated with this test of this null hypothesis is 0.05 . A $10 \%$ adjustment for drop-outs resulted in a sample size of 100 patients each in the experimental group and the control group.

SPSS software for Windows version 19.0 was utilized to perform statistical analysis. Baseline characteristics of the treatment groups were compared using the t-test or Mann-Whitney U-test for continuous variables and the $\chi^{2}$ test or Fisher's exact test for categorical variables. The Kaplan-Meier method and log-rank test were performed for survival analysis. A two-sided $P$-value of $<0.05$ was considered significant. Estimates are reported with the 95\% confidence interval (CI) where appropriate. The date of randomization was used as the starting point for all time to event variables. All analyses were performed according to the intention to treat.

\section{Results}

\section{Patient characteristics}

A total of 86 patients were eligible and enrolled between October 2010 and March 2015. Because recruitment in this trial was slower than expected, we elected to perform an unplanned interim analysis. Among these 86 patients, 41 patients were randomized to the PF group (arm A), and 45 patients were randomized to the DP group (arm B) (Figure 2). Baseline clinical characteristics of the 86 patients are listed in Table 1. All pretreatment characteristics were well balanced between the two groups.

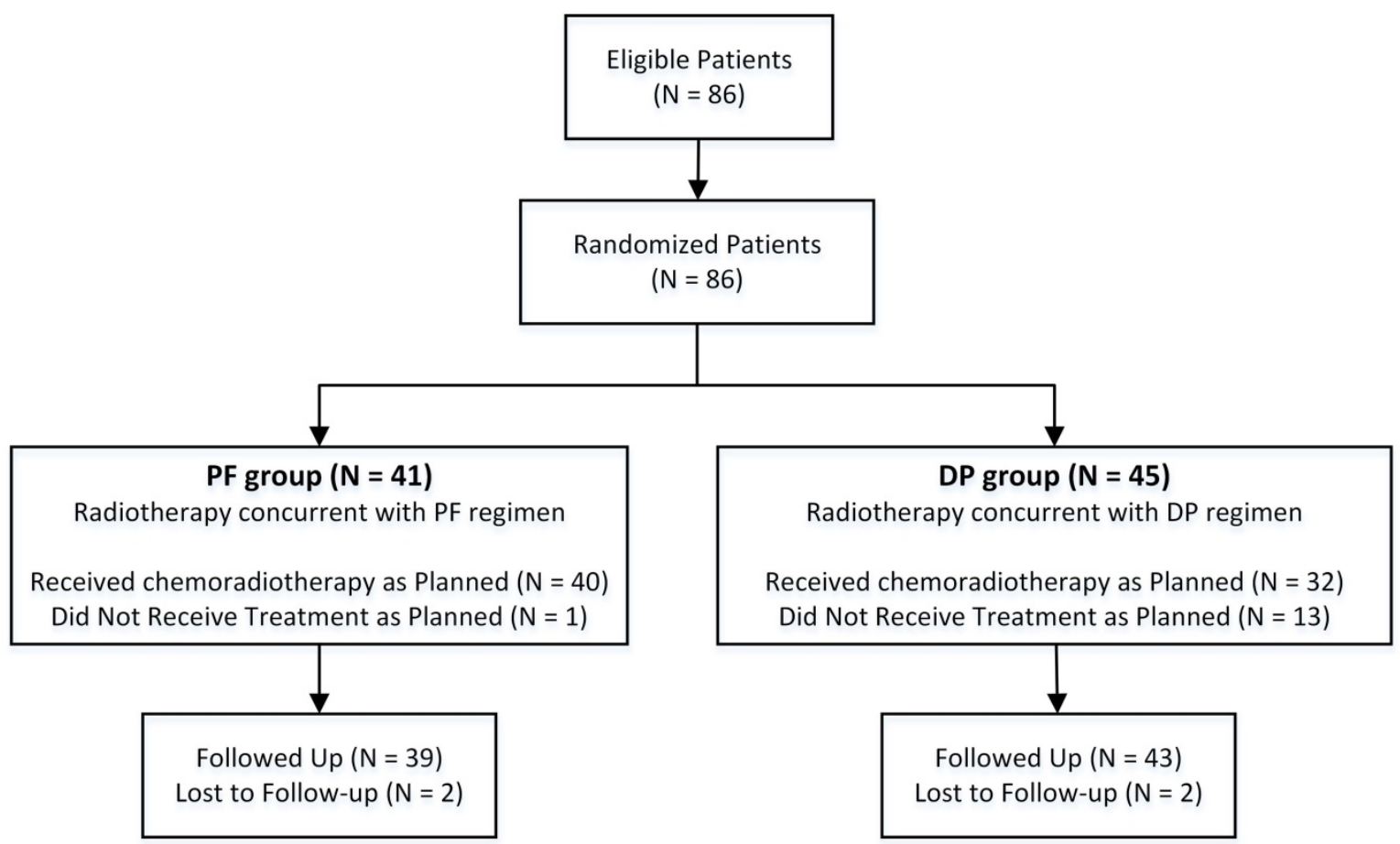

Figure 2. Trial profile. DP, docetaxel plus cisplatin; PF, cisplatin plus 5-FU. 
Table 1. Baseline clinical characteristics of the PF group and the DP group

\begin{tabular}{|c|c|c|c|}
\hline Variable & $\begin{array}{l}\text { PF group }(\mathrm{N}=41) \\
\mathrm{n}(\%)\end{array}$ & $\begin{array}{l}\text { DP group }(\mathrm{N}=45) \\
\mathrm{n}(\%)\end{array}$ & $P$-value \\
\hline \multicolumn{4}{|l|}{ Gender } \\
\hline Male & $29(70.7)$ & $31(68.9)$ & 0.853 \\
\hline Female & $12(29.3)$ & $14(31.1)$ & \\
\hline \multicolumn{4}{|l|}{ Age (years) } \\
\hline Median (range) & $59(45-69)$ & $58(40-73)$ & \\
\hline$<60$ & $25(61.0)$ & $27(60.0)$ & 0.926 \\
\hline$\geq 60$ & $16(39.0)$ & $18(40.0)$ & \\
\hline \multicolumn{4}{|l|}{ KPS } \\
\hline 90 & $33(80.5)$ & $39(86.7)$ & 0.370 \\
\hline 80 & $8(19.5)$ & $5(11.1)$ & \\
\hline 70 & $0(0)$ & $1(2.2)$ & \\
\hline \multicolumn{4}{|l|}{ BMI $\left(\mathrm{kg} / \mathrm{m}^{2}\right)$} \\
\hline Median (range) & $21.5(15.7-30.8)$ & $21.3(17.1-27.5)$ & \\
\hline$<18.5$ & $6(14.6)$ & $4(8.9)$ & 0.508 \\
\hline$\geq 18.5$ & $35(85.4)$ & $41(91.1)$ & \\
\hline \multicolumn{4}{|l|}{ CCI } \\
\hline 0 & $31(75.6)$ & $31(68.9)$ & 0.716 \\
\hline 1 & $10(24.4)$ & $13(28.9)$ & \\
\hline 3 & $0(0)$ & $1(2.2)$ & \\
\hline \multicolumn{4}{|l|}{ Smoking index } \\
\hline 0 & $15(36.6)$ & $20(44.4)$ & 0.755 \\
\hline$>0, \leq 400$ & $10(24.4)$ & $10(22.2)$ & \\
\hline$>400$ & $16(39.0)$ & $15(33.3)$ & \\
\hline \multicolumn{4}{|l|}{ Drinking } \\
\hline No & $28(68.3)$ & $30(66.7)$ & 0.872 \\
\hline Yes & $13(31.7)$ & $15(33.3)$ & \\
\hline \multicolumn{4}{|l|}{ Tumour location } \\
\hline Cervical & $7(17.1)$ & $5(11.1)$ & 0.729 \\
\hline Upper thoracic & $13(31.7)$ & $19(42.2)$ & \\
\hline Middle thoracic & $16(39.0)$ & $15(33.3)$ & \\
\hline Lower thoracic & $3(7.3)$ & $2(4.4)$ & \\
\hline Multiple primary & $2(4.9)$ & $4(8.9)$ & \\
\hline \multicolumn{4}{|c|}{ Tumour length (mm) } \\
\hline Median (range) & $55(10-150)$ & $47(20-96)$ & \\
\hline \multicolumn{4}{|l|}{ TNM stage * } \\
\hline IIA, IIB & $4(9.8)$ & $9(20.0)$ & 0.236 \\
\hline III & $26(63.4)$ & $21(46.7)$ & \\
\hline IVA & $11(26.8)$ & $15(33.3)$ & \\
\hline
\end{tabular}

Abbreviations: $\mathrm{BMI}=$ body mass index; $\mathrm{CCI}=$ Charlson comorbidity index; $\mathrm{KPS}=$ Karnofsky performance status; $\mathrm{PF}=$ cisplatin $+5-\mathrm{Fu}$; $\mathrm{DP}=$ docetaxel + cisplatin; ${ }^{*}$ TNM stage was assessed according to the $6^{\text {th }}$ edition of the American Joint Commission on Cancer (AJCC) staging system.

Table 2. Treatment information for the PF group and DP group

\begin{tabular}{|c|c|c|c|}
\hline Variable & $\begin{array}{l}\text { PF group }(\mathrm{N}=41) \\
\mathrm{n}(\%)\end{array}$ & $\begin{array}{l}\text { DP group }(\mathrm{N}=45) \\
\mathrm{n}(\%)\end{array}$ & $P$-value \\
\hline \multicolumn{4}{|l|}{ Radiotherapy techniques } \\
\hline 3D-CRT & $6(14.6)$ & $12(26.7)$ & 0.171 \\
\hline IMRT & $35(85.4)$ & $33(73.3)$ & \\
\hline \multicolumn{4}{|l|}{ Radiation dose (Gy) } \\
\hline Median (range) & $60.0(56.0-64.0)$ & $60.0(55.8-64.0)$ & \\
\hline \multicolumn{4}{|l|}{ Treatment compliance } \\
\hline As planned & $40(97.6)$ & $32(71.1)$ & 0.002 \\
\hline $\begin{array}{l}\text { Second cycle of } \\
\text { chemotherapy reduced }\end{array}$ & $0(0)$ & $8(17.8)$ & \\
\hline $\begin{array}{l}\text { Second cycle of } \\
\text { chemotherapy changed }\end{array}$ & $1(2.4)$ & $3(6.7)$ & \\
\hline $\begin{array}{l}\text { Second cycle of } \\
\text { chemotherapy cancelled }\end{array}$ & $0(0)$ & $2(4.4)$ & \\
\hline
\end{tabular}

Abbreviations: $3 \mathrm{D}-\mathrm{CRT}=$ three-dimensional conformal radiotherapy; IMRT = intensity-modulated radiotherapy.

\section{Treatment}

Treatment information for the two arms is presented in Table 2. In the PF group, six (14.6\%) patients received 3D-CRT, and 35 (85.4\%) received IMRT. In the DP group, $12(26.7 \%)$ patients received $3 \mathrm{D}-\mathrm{CRT}$, and $33(73.3 \%)$ received IMRT. The median radiation doses of the PF and DP groups were $60.0 \mathrm{~Gy}$ (range, 56.0 to $64.0 \mathrm{~Gy}$ ) and 60.0 Gy (range, 55.8 to 64.0 Gy), respectively. All patients completed radiotherapy as planned. Forty $(97.6 \%)$ patients in the PF group and $32(71.1 \%)$ patients in the DP group received chemotherapy at full-dose intensity for two cycles as planned $(P=0.002)$. Among patients in the DP group, eight $(17.8 \%)$ experienced dose reduction, three $(6.7 \%)$ received an altered regimen, and two $(4.4 \%)$ cancelled chemotherapy during the second cycle. In contrast, only one $(2.4 \%)$ patient in the PF group received an altered regimen during his second cycle of chemotherapy.

\section{Treatment outcome}

Of the 41 patients in the PF group, 12 (29.3\%) achieved complete remission (CR) and 24 (58.5\%) achieved partial remission (PR), four $(9.8 \%)$ patients had stable disease (SD), and one $(2.4 \%)$ patient experienced progressive disease (PD). Of patients in the DP group, $14(31.1 \%), 24$ (53.3\%), 5 (11.1\%) and 2 $(4.4 \%)$ had $\mathrm{CR}, \mathrm{PR}, \mathrm{SD}$, and $\mathrm{PD}$, respectively. The treatment response was comparable between the two groups $(P=0.980)$ (Figure 3$)$. The overall response rate (ORR: $\mathrm{CR}+\mathrm{PR}$ ) was $84.4 \%$ in the DP group and $87.3 \%$ in the PF group $(P=0.653)$.

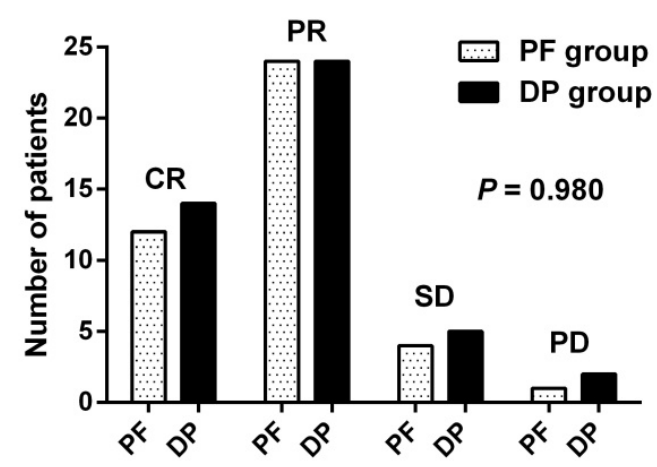

Figure 3. Treatment response of the DP group $(n=45)$ and the PF group $(n=$ 41). CR, complete remission; DP, docetaxel plus cisplatin; PD, progressive disease; PF, cisplatin plus 5-FU; PR, partial remission; SD, stable disease.

As shown in Figure 2, two (4.9\%) patients in the PF group and two (4.4\%) patients in the DP group were lost to follow-up. The median follow-up time was 25.1 months (range, 5.4 - 56.8 months) for the remaining 82 patients with complete follow-up information. A total of $25(30.5 \%)$ patients died during the follow-up period, and all deaths were attributed 
to oesophageal cancer. No treatment-related death was observed. The median survival was not reached in both groups. Prognosis was comparable between the two groups. The 1-year and 2-year OS rates were $93.7 \% \pm 4.3 \%$ and $86.2 \% \pm 6.5 \%$ for the PF group, and $87.3 \% \pm 5.4 \%$ and $69.1 \% \pm 7.9 \%$ for the DP group $(P=$ $0.364)$, respectively (Figure 4A). The 1-year and 2-year PFS rates were $77.4 \% \pm 7.1 \%$ and $55.0 \% \pm 9.3 \%$ for the $\mathrm{PF}$ group, and $78.8 \% \pm 6.3 \%$ and $69.4 \% \pm 7.5 \%$ for the DP group $(P=0.845)$, respectively (Figure $4 \mathrm{~B})$.
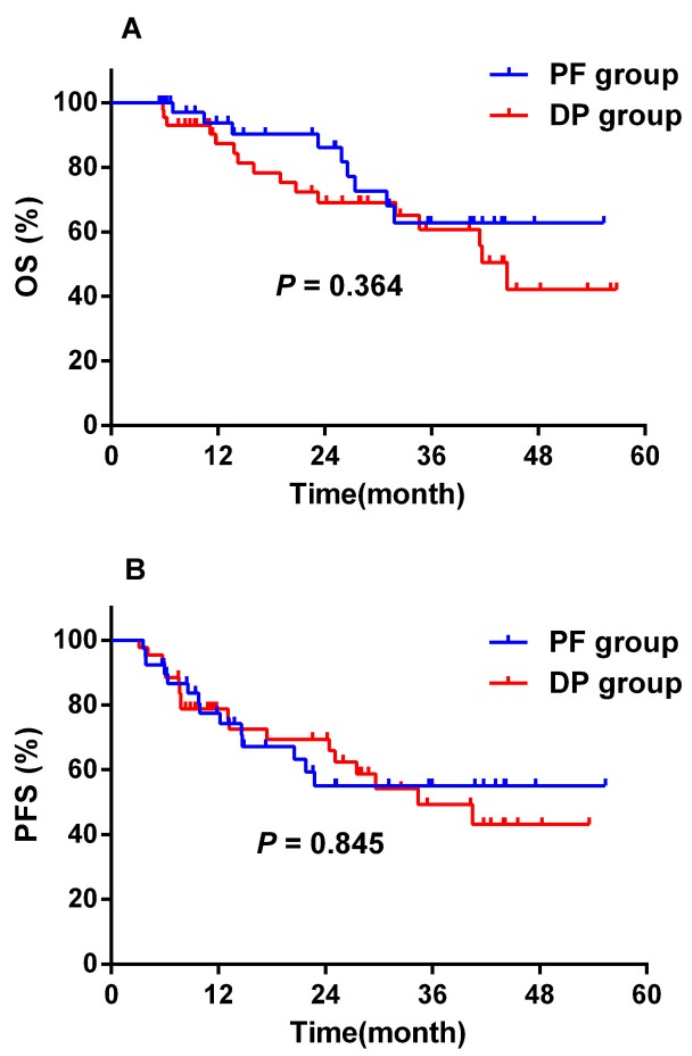

Figure 4. Overall survival $(A)$ and progression-free survival $(B)$ of the DP group $(n=43)$ and the PF group $(n=3)$. DP, docetaxel plus cisplatin; OS, overall survival; PF, cisplatin plus 5-FU; PFS, progression-free survival.

\section{Patterns of failure}

Assessment of the first treatment failure was available for all patients (Table 3). In the PF group, 12 $(29.3 \%)$ patients experienced locoregional failure only, four $(9.8 \%)$ patients had distant failure only, and the remaining $25(61.0 \%)$ patients had no treatment failure during the follow-up period. In the DP group, five $(11.1 \%)$ patients had locoregional failure only, 11 (24.4\%) patients had distant failure only, and four (8.9\%) patients experienced both locoregional and distant failure. Twelve (29.3\%) patients in the PF group and $9(20 \%)$ patients in the DP group experienced locoregional failure as their first treatment failure $(P=0.318)$. However, significantly more patients in the DP group developed distant metastasis than in the PF group at the time of first failure $(33.3 \%$ vs. $9.8 \%, P=0.008)$.

Table 3. Location of disease at first treatment failure and patterns of failure

\begin{tabular}{llll}
\hline First failure & $\begin{array}{l}\text { PF group }(\mathrm{N}=41) \\
\mathrm{n}(\%)\end{array}$ & $\begin{array}{l}\text { DP group }(\mathrm{N}=45) \\
\mathrm{n}(\%)\end{array}$ & $P$-value \\
$\begin{array}{l}\text { Location of disease at first treatment failure } \\
\text { Local-regional only }\end{array}$ & $12(29.3 \%)$ & $5(11.1 \%)$ & \\
$\begin{array}{l}\text { Distant only } \\
\text { Local-regional and distant }\end{array}$ & $4(9.8 \%)$ & $11(24.4 \%)$ & \\
$\begin{array}{l}\text { Patterns of failure } \\
\text { Local-regional failure }\end{array}$ & $12(29.0 \%)$ & $4(8.9 \%)$ & \\
Distant failure & $4(9.8 \%)$ & $9(20.0 \%)$ & 0.318 \\
\hline
\end{tabular}

\section{Treatment-related toxicities}

Acute treatment-related toxicities are listed in Table 4. Grade 3/4 leukocytopenia/neutropenia was significantly more common in the DP group than in the PF group $(68.9 \%$ vs. $19.5 \%, P<0.001)$. Grade $\geq 2$ anaemia was also more frequently observed in the DP group than in the PF group $(64.4 \%$ vs. $24.4 \%, P<$ 0.001). In addition, grade 1 liver enzyme elevation was more common in the DP group than in the PF group $(44.4 \%$ vs. $22.0 \%, P=0.028)$. The incidence and severity of other toxicities, including thrombocytopenia, nausea and vomiting, oesophagitis and radiation pneumonitis, were all comparable between the two groups.

\section{Discussion}

In this randomized study, we compared the efficacy and toxicity of definitive CCRT with the DP regimen with the efficacy and toxicity of CCRT with the PF regimen in patients with locoregional ESCC. Our findings showed that definitive CCRT with the $\mathrm{DP}$ or PF regimen was comparable in terms of ORR, OS, and PFS. The completion rate of chemotherapy at full-dose intensity was significantly lower for those who received the DP regimen than for those who received the PF regimen. In addition, a significantly higher incidence of grade $\geq 3$ leukocytopenia/ neutropenia, grade $\geq 2$ anaemia, or grade 1 liver function impairment was observed among patients receiving the DP regimen than among those receiving the PF regimen.

According to the result of RTOG 85-01 5-7, concurrent chemoradiotherapy has been established as one of the standard treatment options for locally advanced oesophageal cancer. Although compared with radiotherapy alone, CCRT significantly improved locoregional control and OS, the treatment outcome of CCRT remained to be improved. For instance, the locoregional failure of the CCRT arm in RTOG $85-01$ was as high as $47 \%$, and the 5 -year OS 
was only $26 \%$. Several RTOG studies have sought to improve the outcome of CCRT by increasing the radiation dose, including the RTOG 90-12 phase II study ( $\mathrm{PF}$ regimen plus radiotherapy at $64.8 \mathrm{~Gy}$ ), the RTOG 92-07 phase I/II study (PF regimen plus radiotherapy at 50 Gy with a brachytherapy boost), and the RTOG 94-05 phase III study (PF regimen plus radiotherapy at 64.8 Gy vs. $50.4 \mathrm{~Gy}$ ). However, none of these studies demonstrated a definitive advantage over the result of RTOG 85-01 in terms of locoregional control or survival. Moreover, the incidence of treatment-related mortality was increased. Another strategy to improve the efficacy of CCRT involved intensifying the chemotherapy. However, previous studies incorporating more intensive regimens did not improve the efficacy and resulted in relatively high treatment-related mortality, including those with an increased dose intensity of 5-FU 9 , additional cycles of chemotherapy before or after CCRT ${ }^{9}$, or novel cytotoxic agents, such as paclitaxel and oxaliplatin 2,10.

Table 4. Incidence of acute treatment-related toxicities

\begin{tabular}{|c|c|c|c|}
\hline & $\begin{array}{l}\text { PF group }(\mathrm{N}=41) \\
\mathrm{n}(\%)\end{array}$ & $\begin{array}{l}\text { DP group }(\mathrm{N}=45) \\
\mathrm{n}(\%)\end{array}$ & $P$-value \\
\hline \multicolumn{4}{|c|}{$\begin{array}{l}\text { Leukocytopenia / } \\
\text { Neutropenia }\end{array}$} \\
\hline Grade 0 & $2(4.9)$ & $2(4.4)$ & 0.000 \\
\hline Grade 1 & $5(12.2)$ & $5(11.1)$ & \\
\hline Grade 2 & $26(63.4)$ & $7(15.6)$ & \\
\hline Grade 3 & $8(19.5)$ & $5(11.1)$ & \\
\hline Grade 4 & $0(0.0)$ & $26(57.8)$ & \\
\hline \multicolumn{4}{|c|}{ Thrombocytopenia } \\
\hline Grade 0 & $19(46.3)$ & $17(37.8)$ & 0.608 \\
\hline Grade 1 & $11(26.8)$ & $14(31.1)$ & \\
\hline Grade 2 & $10(24.4)$ & $7(20.0)$ & \\
\hline Grade 3 & $1(2.4)$ & $3(6.7)$ & \\
\hline Grade 4 & $0(0.0)$ & $2(4.4)$ & \\
\hline \multicolumn{4}{|l|}{ Anaemia } \\
\hline Grade 0 & $7(17.1)$ & $2(4.4)$ & 0.000 \\
\hline Grade 1 & $24(58.5)$ & $14(31.1)$ & \\
\hline Grade 2 & $7(17.1)$ & $27(60.0)$ & \\
\hline Grade 3 & $3(7.3)$ & $2(4.4)$ & \\
\hline \multicolumn{4}{|c|}{ Nausea and vomiting } \\
\hline Grade 0 & $3(7.3)$ & $1(2.2)$ & 0.217 \\
\hline Grade 1 & $21(51.2)$ & $24(53.3)$ & \\
\hline Grade 2 & $11(26.8)$ & $18(40.0)$ & \\
\hline Grade 3 & $6(14.6)$ & $2(4.4)$ & \\
\hline \multicolumn{4}{|c|}{ Liver enzyme elevation } \\
\hline Grade 0 & $32(78.0)$ & $25(55.6)$ & 0.028 \\
\hline Grade 1 & $9(22.0)$ & $20(44.4)$ & \\
\hline \multicolumn{4}{|c|}{ Oesophagitis } \\
\hline Grade 0 & $2(4.9)$ & $0(0.0)$ & 0.496 \\
\hline Grade 1 & $13(31.7)$ & $11(24.4)$ & \\
\hline Grade 2 & $11(26.8)$ & $15(33.3)$ & \\
\hline Grade 3 & $15(36.6)$ & $18(40.0)$ & \\
\hline Grade 4 & $0(0.0)$ & $1(2.2)$ & \\
\hline \multicolumn{4}{|c|}{ Radiation pneumonitis } \\
\hline Grade 0 & $30(73.2)$ & $34(75.6)$ & 0.436 \\
\hline Grade 1 & $6(14.6)$ & $7(15.6)$ & \\
\hline Grade 2 & $1(2.4)$ & $3(6.7)$ & \\
\hline Grade 3 & $4(9.8)$ & $1(2.2)$ & \\
\hline
\end{tabular}

Note: Acute toxicities were evaluated according to the Common Terminology Criteria for Adverse Events version 3.0 (CTCAE 3.0).
Docetaxel is a semi-synthetic taxane with promising single-agent activity in advanced oesophageal cancer ${ }^{17}$. In vitro studies have also demonstrated that docetaxel enhances radiosensitivity via inducing mitotic arrest and apoptosis in murine tumour cells 11,18 . Several studies have reported promising efficacy of docetaxel and cisplatin (the DP regimen) in oesophageal cancer 13-16. Two previous studies revealed significant survival advantages of the DP regimen over the PF regimen in CCRT for patients with locally advanced oesophageal cancer ${ }^{13}, 14$. However, the PF regimens reported in those two studies were dose-reduced, and no randomized study has compared the treatment outcome of DP regimen and standard-dose PF regimen concurrent with radiotherapy in oesophageal cancer. To our knowledge, the present study is the first prospective randomized trial focusing on this particular issue.

Numerous studies have assessed the clinical outcome of CCRT in patients with oesophageal cancer. Prospective studies and selected retrospective studies are listed in Table 5. In those studies, the reported ORR ranged from $53.3 \%$ to $98.3 \%$. In studies incorporating the PF regimen, the ORR in the PF group was $53.3 \%$ to $87 \% 2,9,14,19-21$. The ORR in patients receiving radiotherapy combined with the DP regimen was $73.3 \%$ to $98.3 \% 14,15$. Our result showed that the ORR was $84.4 \%$ in the DP group and $87.3 \%$ in the PF group, indicating a comparable rate between groups $(P=0.653)$.

In patients receiving the PF regimen concurrent with radiotherapy, the median survival time was 9 to 29 months, the 1 -year OS rate varied from $31 \%$ to $52 \%$, and the 2 -year OS rate was $31.5 \%$ to $46 \%$ (Table 5). In our study, the median survival time was not achieved in the PF group, and the 1-year and 2-year OS rate were $93.7 \%$ and $86.2 \%$, respectively, which seemed to be superior to the previously reported results. Several factors might account for this discrepancy between studies. First, the dose intensity of the chemotherapy regimen varied between studies. For instance, in Zhang's study, patients in the PF group received a lower dose of cisplatin and 5-FU (CDDP $60 \mathrm{mg} / \mathrm{m}^{2} \mathrm{~d} 1$ + 5-FU $300 \mathrm{~g} / \mathrm{m}^{2} / \mathrm{d}$ d1-d3, Q4W) than in our study (CDDP $80 \mathrm{mg} / \mathrm{m}^{2} \mathrm{~d} 1+5-\mathrm{FU} 1,000 \mathrm{~g} / \mathrm{m}^{2} / \mathrm{d} \mathrm{d} 1-\mathrm{d} 4$, Q3W) ${ }^{13}$. Second, the radiation techniques also differed between studies. In our study, most patients $(35,85.4 \%)$ received IMRT, which has been reported to provide superior coverage of the PTV, better dosimetric results, and better treatment outcomes than 3D-CRT or conventional two-dimensional radiotherapy (2DRT) 22-24. Finally, patient selection bias might exist especially for retrospective studies. 
Table 5. Studies on definitive radiotherapy with or without chemotherapy for oesophageal cancer patients.

\begin{tabular}{|c|c|c|c|c|c|c|c|c|c|c|c|c|c|c|}
\hline Study & & Pathology & Stage & $\mathrm{N}$ & Treatment (n) & $\begin{array}{l}\text { Radiation } \\
\text { dose (Gy) }\end{array}$ & Chemotherapy regimen & ORR & $\begin{array}{l}\text { MST } \\
\text { (month) }\end{array}$ & $\begin{array}{l}1 \text { year } \\
\text { OS }\end{array}$ & $\begin{array}{l}2 \text { year } \\
\text { OS }\end{array}$ & $\begin{array}{l}3 \text { year } \\
\text { OS }\end{array}$ & $\begin{array}{l}5 \text { year } \\
\text { OS }\end{array}$ & $\begin{array}{l}\text { Completion } \\
\text { rate }\end{array}$ \\
\hline Herskovic & Prospective & Sq/Ad & T1-3 & 123 & RT alone (62) & 64 & / & / & 9.3 & $34 \%$ & $10 \%$ & $0 \%$ & $0 \%$ & $58 \%$ \\
\hline $\begin{array}{l}\text { A, } 1992 \text {; } \\
\text { al-Sarraf } \\
\text { M, } 1997 \text {; } \\
\text { Cooper JS, } \\
1999^{5}\end{array}$ & $\begin{array}{l}\text { Randomized } \\
\text { (RTOG 85-01) }\end{array}$ & & $\begin{array}{l}\text { N0-1 } \\
\text { M0 }\end{array}$ & & $\begin{array}{l}\mathrm{RT}+\mathrm{CT}(\mathrm{PF}) \\
(61)\end{array}$ & 50 & $\begin{array}{l}\text { CDDP 75mg } / \mathrm{m}^{2} \mathrm{~d} 1+5-\mathrm{FU} \\
1 \mathrm{~g} / \mathrm{m}^{2} / \mathrm{d} \text { d1-d4, Q4W }\end{array}$ & / & 14.1 & $52 \%$ & $36 \%$ & $30 \%$ & $26 \%$ & $36 \%$ \\
\hline $\begin{array}{l}\text { Minsky } \\
\text { BD, } 1996 \text {; } \\
\text { Minsky } \\
\text { BD, } 1999 \\
21\end{array}$ & $\begin{array}{l}\text { Prospective } \\
\text { (INT 0122) }\end{array}$ & Sq & $\begin{array}{l}\text { T1-4 } \\
\text { N0-1 } \\
\text { M0 }\end{array}$ & 38 & $\begin{array}{l}\mathrm{CT}(\mathrm{PF}) \rightarrow \mathrm{RT}+ \\
\mathrm{CT}(\mathrm{PF})(38)\end{array}$ & 64.8 & $\begin{array}{l}\text { Neoadjuvant segment: } \\
\text { CDDP } 100 \mathrm{mg} / \mathrm{m}^{2} \mathrm{~d} 1+5-\mathrm{FU} \\
1 \mathrm{~g} / \mathrm{m}^{2} / \mathrm{d} \mathrm{d} 1-\mathrm{d} 5, \mathrm{Q} 4 \mathrm{~W} ; \\
\text { Combined modality } \\
\text { segment: CDDP } 75 \mathrm{mg} / \mathrm{m}^{2} \\
\mathrm{~d} 1+5-\mathrm{FU} 1 \mathrm{~g} / \mathrm{m}^{2} / \mathrm{d} \mathrm{d} 1-\mathrm{d} 5 \text {, } \\
\text { Q4W }\end{array}$ & $55 \%$ & 20 & / & / & $30 \%$ & $20 \%$ & $42 \%$ \\
\hline $\begin{array}{l}\text { Atsushi } \\
\text { Ohtsu, } \\
199920\end{array}$ & Prospective & $\mathrm{Sq}$ & $\begin{array}{l}\text { T4/M } \\
1 \\
\text { LYM }\end{array}$ & 54 & $\begin{array}{l}\mathrm{RT}+\mathrm{CT}(\mathrm{PF}) \\
(54)\end{array}$ & 60 & $\begin{array}{l}\text { CDDP } 40 \mathrm{mg} / \mathrm{m}^{2} \mathrm{~d} 1, \mathrm{~d} 8+ \\
5-\mathrm{FU} 400 \mathrm{mg} / \mathrm{m}^{2} / \mathrm{d} \\
\mathrm{d} 1-\mathrm{d} 5, \mathrm{~d} 8-\mathrm{d} 12, \mathrm{Q} 5 \mathrm{~W}\end{array}$ & $87 \%$ & 9 & $41 \%$ & / & $23 \%$ & / & $91 \%$ \\
\hline \multirow[t]{2}{*}{$\begin{array}{l}\text { Minsky } \\
\text { BD, } 2002^{4}\end{array}$} & $\begin{array}{l}\text { Prospective } \\
\text { (INT 0123) } \\
\text { (RTOG 94-05) }\end{array}$ & $\mathrm{Sq} / \mathrm{Ad}$ & $\begin{array}{l}\text { T1-4 } \\
\text { N0-1 } \\
\text { M0 }\end{array}$ & 218 & $\begin{array}{l}\text { RT } \\
\text { (Standard-Dose } \\
)+\mathrm{CT}(\mathrm{PF}) \\
(109)\end{array}$ & 50.4 & $\begin{array}{l}\text { CDDP } 75 \mathrm{mg} / \mathrm{m}^{2} \mathrm{~d} 1+5-\mathrm{FU} \\
1 \mathrm{~g} / \mathrm{m}^{2} / \mathrm{d} \text { d1-d4, Q4W }\end{array}$ & / & 18.1 & $40 \%$ & / & / & / & / \\
\hline & & & & & $\begin{array}{l}\text { RT (High-Dose) } \\
+ \text { CT (PF) (109) }\end{array}$ & 64 & $\begin{array}{l}\text { CDDP } 75 \mathrm{mg} / \mathrm{m}^{2} \mathrm{~d} 1+5-\mathrm{FU} \\
1 \mathrm{~g} / \mathrm{m}^{2} / \mathrm{d} \mathrm{d} 1-\mathrm{d} 4, \mathrm{Q} 4 \mathrm{~W}\end{array}$ & / & 13 & $31 \%$ & / & / & / & / \\
\hline $\begin{array}{l}\text { Ishida K, } \\
2004^{19}\end{array}$ & Prospective & $\mathrm{Sq}$ & $\begin{array}{l}\text { T4/M } \\
1 \\
\text { LYM }\end{array}$ & 60 & $\begin{array}{l}\mathrm{RT}+\mathrm{CT}(\mathrm{PF}) \\
(60)\end{array}$ & 60 & $\begin{array}{l}\mathrm{CDDP} 70 \mathrm{mg} / \mathrm{m}^{2} \mathrm{~d} 1+5-\mathrm{FU} \\
700 \mathrm{mg} / \mathrm{m}^{2} / \mathrm{d} \mathrm{d} 1-\mathrm{d} 4, \mathrm{Q} 4 \mathrm{~W}\end{array}$ & $68.3 \%$ & 10 & / & $31.5 \%$ & / & / & $77 \%$ \\
\hline \multirow[t]{2}{*}{$\begin{array}{l}\text { Ajani JA, } \\
200810\end{array}$} & $\begin{array}{l}\text { Prospective } \\
\text { randomized }\end{array}$ & $\mathrm{Sq} / \mathrm{Ad}$ & $\begin{array}{l}\text { Locali } \\
\text { zed }\end{array}$ & 72 & $\begin{array}{l}\mathrm{CT}(\mathrm{TPF}) \rightarrow \mathrm{RT} \\
+\mathrm{CT}(\mathrm{TF})(37)\end{array}$ & 50.4 & / & & 28.7 & $75.7 \%$ & $55.9 \%$ & & & \\
\hline & (RTOG 0113) & & & & $\begin{array}{l}\mathrm{CT}(\mathrm{TP}) \rightarrow \mathrm{RT}+ \\
\mathrm{CT}(\mathrm{TP})(35)\end{array}$ & 50.4 & / & & 14.9 & $68.6 \%$ & $36.9 \%$ & & & \\
\hline $\begin{array}{l}\mathrm{Li} Q Q \\
2010^{15}\end{array}$ & Retrospective & $\mathrm{Sq}$ & II - IV & 59 & $\begin{array}{l}\mathrm{RT}+\mathrm{CT}(\mathrm{DP}) \\
(59)\end{array}$ & $50-64$ & $\begin{array}{l}\text { Docetaxel } 60 \mathrm{mg} / \mathrm{m}^{2} \mathrm{~d} 1+ \\
\text { CDDP } 80 \mathrm{mg} / \mathrm{m}^{2} \mathrm{~d} 1 \text {, Q3W }\end{array}$ & $98.3 \%$ & 22.6 & / & / & $36.7 \%$ & / & / \\
\hline $\begin{array}{l}\text { Kato K, } \\
201122\end{array}$ & $\begin{array}{l}\text { Prospective } \\
\text { (JCOG 9906) }\end{array}$ & $\mathrm{Sq}$ & II - III & 74 & $\begin{array}{l}\mathrm{RT}+\mathrm{CT}(\mathrm{PF}) \\
(74)\end{array}$ & 60 & $\begin{array}{l}\text { CDDP } 40 \mathrm{mg} / \mathrm{m}^{2} \mathrm{~d} 1, \mathrm{~d} 8+ \\
5-\mathrm{FU} 400 \mathrm{mg} / \mathrm{m}^{2} / \mathrm{d} \\
\mathrm{d} 1-\mathrm{d} 5, \mathrm{~d} 8-\mathrm{d} 12, \mathrm{Q} 5 \mathrm{~W}\end{array}$ & $\begin{array}{l}66.2 \% \\
(\mathrm{CR})\end{array}$ & 29 & / & / & $44.7 \%$ & / & / \\
\hline \multirow[t]{2}{*}{$\begin{array}{l}\text { Nishimur } \\
\text { a Y, } 2012 \\
23\end{array}$} & $\begin{array}{l}\text { Prospective } \\
\text { (KROSG0101/ } \\
\text { JROSG021) }\end{array}$ & $\begin{array}{l}\mathrm{Sq} \\
(90) / \mathrm{Ad} \\
(1)\end{array}$ & $\begin{array}{l}\text { II - } \\
\text { IVa }\end{array}$ & 91 & $\begin{array}{l}\mathrm{RT}+\mathrm{CT}(\mathrm{PF}) \\
(\text { full dose } \\
\text { short-term) (46) }\end{array}$ & 60 & $\begin{array}{l}\mathrm{CDDP} 70 \mathrm{mg} / \mathrm{m}^{2} \mathrm{~d} 1+5-\mathrm{FU} \\
700 \mathrm{mg} / \mathrm{m}^{2} / \mathrm{d} \mathrm{d} 1-\mathrm{d} 5, \mathrm{Q} 4 \mathrm{~W}\end{array}$ & / & / & / & $46 \%$ & / & $35 \%$ & $89 \%$ \\
\hline & & & & & $\begin{array}{l}\mathrm{RT}+\mathrm{CT}(\mathrm{PF}) \\
\text { (low-dose } \\
\text { protracted) (45) }\end{array}$ & 60 & $\begin{array}{l}\text { CDDP } 7 \text { mg/m² } \\
\text { d1-d5,d8-d12 + 5-FU } 250 \\
\mathrm{mg} / \mathrm{m}^{2} / \mathrm{d} \text { d1-d14, Q4W }\end{array}$ & / & / & / & $44 \%$ & / & $22 \%$ & $71 \%$ \\
\hline \multirow[t]{2}{*}{$\begin{array}{l}\text { Zhao T, } \\
2012{ }^{14}\end{array}$} & Prospective & $\mathrm{Sq}$ & $\begin{array}{l}\text { II - } \\
\text { IVa }\end{array}$ & 90 & $\begin{array}{l}\mathrm{RT}+\mathrm{CT}(\mathrm{PF}) \\
(45)\end{array}$ & 50.4 & $\begin{array}{l}\text { CDDP } 75 \mathrm{mg} / \mathrm{m}^{2} \mathrm{~d} 1+5-\mathrm{FU} \\
250 \mathrm{mg} / \mathrm{m}^{2} / \mathrm{d} \text { d1-d4, Q4W }\end{array}$ & $53.3 \%$ & 22.3 & / & / & / & / & $80 \%$ \\
\hline & & & & & $\begin{array}{l}\text { RT + CT (DP) } \\
(45)\end{array}$ & 50.4 & $\begin{array}{l}\text { Docetaxel } 75 \mathrm{mg} / \mathrm{m}^{2} \mathrm{~d} 1+ \\
\text { CDDP } 75 \mathrm{mg} / \mathrm{m}^{2} \mathrm{~d} 1, \mathrm{Q} 4 \mathrm{~W}\end{array}$ & $73.3 \%$ & 43.2 & / & / & / & / & $73.3 \%$ \\
\hline $\begin{array}{l}\text { Higuchi } \\
\text { K, } 2014{ }^{24}\end{array}$ & Prospective & Sq & $\begin{array}{l}\text { T4/M } \\
1 \\
\text { LYM }\end{array}$ & 42 & $\begin{array}{l}\mathrm{RT}+\mathrm{CT}(\mathrm{DCF}) \\
\rightarrow \mathrm{CT}(\mathrm{DCF}) \\
(42)\end{array}$ & $\begin{array}{l}61.2(12), \\
50.4(30)\end{array}$ & / & $85.7 \%$ & 29 & $66.1 \%$ & / & $43.9 \%$ & / & $81 \%$ \\
\hline \multirow[t]{2}{*}{$\begin{array}{l}\text { Conroy T, } \\
2014^{2}\end{array}$} & $\begin{array}{l}\text { Prospective } \\
\text { (PRODIGE5/ }\end{array}$ & $\mathrm{Sq} / \mathrm{Ad}$ & I - IVa & 267 & $\begin{array}{l}\text { RT }+ \text { CT } \\
(\text { FOLFOX) (134) }\end{array}$ & 50 & / & $67 \%$ & 20.2 & & & $19.9 \%$ & & $68.7 \%$ \\
\hline & ACCORD17) & & & & $\begin{array}{l}\mathrm{RT}+\mathrm{CT}(\mathrm{PF}) \\
(133)\end{array}$ & 50 & $\begin{array}{l}\text { CDDP } 75 \mathrm{mg} / \mathrm{m}^{2} \mathrm{~d} 1+5-\mathrm{FU} \\
1 \mathrm{~g} / \mathrm{m}^{2} / \mathrm{d} \text { d1-d4, Q3W/Q4W }\end{array}$ & $65 \%$ & 17.5 & & & $26.9 \%$ & & $75 \%$ \\
\hline $\begin{array}{l}\text { Hihara J, } \\
2015^{25}\end{array}$ & Prospective & $\mathrm{Sq}$ & $\begin{array}{l}\text { III - } \\
\text { IV }\end{array}$ & 16 & $\begin{array}{l}\mathrm{RT}+\mathrm{CT}(\mathrm{DF}) \\
(16)\end{array}$ & 66 & $\begin{array}{l}\text { Docetaxel } 7.5 \mathrm{mg} / \mathrm{m}^{2} \mathrm{~d} 1, \mathrm{~d} 8 \\
+5-\mathrm{FU} 250 \mathrm{mg} / \mathrm{m}^{2} / \mathrm{d} \\
\mathrm{d} 1-\mathrm{d} 5, \mathrm{~d} 8-\mathrm{d} 12, \mathrm{Q} 3 \mathrm{~W}\end{array}$ & $94 \%$ & & & & $44 \%$ & $31 \%$ & / \\
\hline \multirow[t]{2}{*}{$\begin{array}{l}\text { Zhang P, } \\
2016^{13}\end{array}$} & Retrospective & $\mathrm{Sq}$ & $\begin{array}{l}\text { II - } \\
\text { IVa }\end{array}$ & 317 & $\begin{array}{l}\mathrm{RT}+\mathrm{CT}(\mathrm{PF}) \\
(156)\end{array}$ & $50-70$ & $\begin{array}{l}\text { CDDP } 60 \mathrm{mg} / \mathrm{m}^{2} \mathrm{~d} 1+5-\mathrm{FU} \\
300 \mathrm{~g} / \mathrm{m}^{2} \mathrm{~d} 1-\mathrm{d} 3, \mathrm{Q} 4 \mathrm{~W}\end{array}$ & / & 24 & $77.4 \%$ & $48.9 \%$ & $32.8 \%$ & / & / \\
\hline & & & & & $\begin{array}{l}\mathrm{RT}+\mathrm{CT}(\mathrm{DP}) \\
(161)\end{array}$ & $50-70$ & $\begin{array}{l}\text { Docetaxel } 60 \mathrm{mg} / \mathrm{m}^{2} \mathrm{~d} 1+ \\
\text { CDDP } 80 \mathrm{mg} / \mathrm{m}^{2} \mathrm{~d} 1, \mathrm{Q} 3 \mathrm{~W} \\
\text { OR Docetaxel } 25 \mathrm{mg} / \mathrm{m}^{2} \mathrm{~d} 1 \\
+ \text { CDDP } 25 \mathrm{mg} / \mathrm{m}^{2} \mathrm{~d} 1, \mathrm{QW}\end{array}$ & / & 21 & & & & & / \\
\hline \multirow[t]{2}{*}{$\begin{array}{l}\text { Current } \\
\text { study }\end{array}$} & Prospective & Sq & $\begin{array}{l}\text { II - } \\
\text { IVa }\end{array}$ & 86 & $\mathrm{RT}+\mathrm{CT}(\mathrm{DP})$ & $\begin{array}{l}60.0 \\
(55.8-64.0)\end{array}$ & $\begin{array}{l}\text { Docetaxel } 60 \mathrm{mg} / \mathrm{m}^{2} \mathrm{~d} 1+ \\
\text { CDDP } 80 \mathrm{mg} / \mathrm{m}^{2} \mathrm{~d} 1, \mathrm{Q} 3 \mathrm{~W}\end{array}$ & $84.4 \%$ & $\begin{array}{l}\text { Not } \\
\text { reached }\end{array}$ & $87.3 \%$ & $69.1 \%$ & / & / & $71.1 \%$ \\
\hline & & & & & $\mathrm{RT}+\mathrm{CT}(\mathrm{PF})$ & $\begin{array}{l}60.0 \\
(56.0-64.0)\end{array}$ & $\begin{array}{l}\text { CDDP } 80 \mathrm{mg} / \mathrm{m}^{2} \mathrm{~d} 1+5-\mathrm{FU} \\
1000 \mathrm{~g} / \mathrm{m}^{2} \mathrm{~d} 1-\mathrm{d} 4, \mathrm{Q} 3 \mathrm{~W}\end{array}$ & $87.8 \%$ & $\begin{array}{l}\text { Not } \\
\text { reached }\end{array}$ & $93.7 \%$ & $86.2 \%$ & / & / & $97.6 \%$ \\
\hline
\end{tabular}

Abbreviations: $\mathrm{Ad}=$ adenocarcinoma; $\mathrm{CT}=$ chemotherapy; $\mathrm{DP}=$ docetaxel + cisplatin, $\mathrm{MST}=$ median survival time; $\mathrm{ORR}=$ overall response rate; $\mathrm{OS}=$ overall survival; $\mathrm{PF}=$ cisplatin + 5-FU; QW = every week; Q3W = every three weeks; Q4W = every four weeks; Q5W = every five weeks; RT = radiotherapy; Sq = squamous cell carcinoma.

On the other hand, for patients receiving the DP regimen concurrent with radiotherapy, the median survival time was 21 to 43.2 months. However, the 1-year and the 2-year OS rates were not in previous studies. Li et al. reported a 3-year OS rate of $36.7 \%$ in a retrospective study ${ }^{15}$. In our study, the 1-year and 2-year OS rates were $87.3 \%$ and $69.1 \%$ in the DP group, respectively, and the median survival time was not achieved. Our results suggest that definitive CCRT with the DP regimen did not improve the 
treatment response or survival in patients with ESCC, which is in conflict with the results of two previous studies. In a randomized study reported in 2012, both the ORR and OS favoured the DP regimen over the PF regimen in CCRT for patients with unresectable locally advanced ESCC ${ }^{14}$. A recent retrospective study using a propensity score-matching method also showed that patients receiving the DP regimen had better OS and PFS than those treated with the PF regimen ${ }^{13}$. Several factors may account for this discrepancy. First, the dosage issue mentioned above might explain this finding. In both previous studies, patients in the PF group received the dose-reduced $\mathrm{PF}$ regimen (CDDP $75 \mathrm{mg} / \mathrm{m}^{2} \mathrm{~d} 1+5-\mathrm{FU} 250 \mathrm{mg} / \mathrm{m}^{2} / \mathrm{d}$ d1-d4, Q4W; CDDP $60 \mathrm{mg} / \mathrm{m}^{2} \mathrm{~d} 1+5-\mathrm{FU} 300 \mathrm{~g} / \mathrm{m}^{2} / \mathrm{d}$ $\mathrm{d} 1-\mathrm{d} 3, \mathrm{Q} 4 \mathrm{~W})$. In the current study, patients received the $\mathrm{PF}$ regimen in a standard dosage (CDDP 80 $\mathrm{mg} / \mathrm{m}^{2} \mathrm{~d} 1+5-\mathrm{FU} 1,000 \mathrm{~g} / \mathrm{m}^{2} / \mathrm{d} \mathrm{d} 1-\mathrm{d} 4$, Q3W) (Table $5)$. The inferior efficacy of the PF regimen compared with the efficacy of the DP regimen reported in those two studies may have resulted from the inadequate dosage of the cytotoxic agents in the PF group. In addition, treatment compliance is another issue. In the present study, only $71.1 \%$ of patients in the DP group completed chemotherapy and radiotherapy at full dosage as planned without treatment interruption, which was much lower than that in the PF group (97.6\%). The poor treatment completion rate might partially contribute to the unsatisfactory result in the DP group.

Severe treatment-related toxicities are the most common cause of treatment interruption or termination. As shown in our study, the most frequent grade $\geq 3$ acute toxicity in the DP group was leukocytopenia / neutropenia (31,68.9\%). Studies in certain types of cancer, such as non-small cell lung cancer, cervical cancer and epithelial ovarian cancer, have demonstrated promising activity and a favourable toxicity profile of weekly chemotherapy regimens ${ }^{25-31}$. Therefore, the weekly schedule of the DP regimen, which may be less toxic and tolerable than the three-week or four-week schedule, should be considered in the future in definitive CCRT for patients with ESCC. Additionally, as the efficacy of standard and pegylated granulocytecolonystimulating factors (G-CSFs) agents in chemotherapy-induced neutropenia (CIN) prophylaxis has been well established in terms of decreasing the risk of CIN and chemotherapy disturbances, primary or secondary prophylactic use of G-CSFs could also be considered in selected patients when prescribing three-week or four-week DP regimen ${ }^{32-34}$. In terms of oesophagitis, the incidence of grade $\geq 3$ toxicity was comparable between the DP group and PF group in our study
$(42.2 \%$ vs. $36.6 \%, P=0.496)$. Overall, no life-threatening toxicity or treatment-related death was observed. Several limitations existed in our study, including the small sample size, slow recruitment, and the inadequate follow-up period. Long term clinical outcomes will be reported later.

\section{Conclusion}

In conclusion, the results of this prospective randomized phase II clinical trial indicate that definitive CCRT with the DP regimen did not improve the treatment response, overall survival or progression-free survival in patients with ESCC compared with the outcomes achieved when using definitive CCRT with the PF regimen. In addition, patients receiving the DP regimen were more likely to develop severe (grade $\geq 3$ ) leukocytopenia/ neutropenia and experience treatment interruption or termination. However, longer follow-up and further phase III trials with larger sample sizes are warranted. Clinicaltrials.gov registration number; NCT 02969473.

\section{Acknowledgements}

This study was funded in part by Medical Scientific Research Foundation of Guangdong Province, China, grant number No. B2014157.

\section{Competing Interests}

The authors have declared that no competing interest exists.

\section{References}

1. Torre LA, Bray F, Siegel RL, Ferlay J, Lortet-Tieulent J, Jemal A. Global cancer statistics, 2012. CA: a cancer journal for clinicians 2015;65(2):87-108.

2. Conroy T, Galais MP, Raoul JL, et al. Definitive chemoradiotherapy with FOLFOX versus fluorouracil and cisplatin in patients with oesophageal cancer (PRODIGE5/ACCORD17): final results of a randomised, phase $2 / 3$ trial. The Lancet Oncology 2014;15(3):305-14.

3. Ruppert BN, Watkins JM, Shirai K, et al. Cisplatin/Irinotecan versus carboplatin/paclitaxel as definitive chemoradiotherapy for locoregionally advanced esophageal cancer. American journal of clinical oncology 2010;33(4):346-52.

4. Minsky BD, Pajak TF, Ginsberg RJ, et al. INT 0123 (Radiation Therapy Oncology Group 94-05) phase III trial of combined-modality therapy for esophageal cancer: high-dose versus standard-dose radiation therapy. Journal of clinical oncology : official journal of the American Society of Clinical Oncology 2002;20(5):1167-74.

5. Cooper JS, Guo MD, Herskovic A, et al. Chemoradiotherapy of locally advanced esophageal cancer: long-term follow-up of a prospective randomized trial (RTOG 85-01). Radiation Therapy Oncology Group. Jama 1999;281(17):1623-7.

6. Herskovic A, Martz K, al-Sarraf M, et al. Combined chemotherapy and radiotherapy compared with radiotherapy alone in patients with cancer of the esophagus. The New England journal of medicine 1992;326(24):1593-8.

7. al-Sarraf $\mathrm{M}$, Martz $\mathrm{K}$, Herskovic A, et al. Progress report of combined chemoradiotherapy versus radiotherapy alone in patients with esophageal cancer: an intergroup study. Journal of clinical oncology : official journal of the American Society of Clinical Oncology 1997;15(1):277-84.

8. Gaspar LE, Winter K, Kocha WI, Coia LR, Herskovic A, Graham M. A phase I/II study of external beam radiation, brachytherapy, and concurrent chemotherapy for patients with localized carcinoma of the esophagus (Radiation Therapy Oncology Group Study 9207): final report. Cancer 2000;88(5):988-95.

9. Minsky BD, Neuberg D, Kelsen DP, Pisansky TM, Ginsberg R, Benson A, 3rd. Neoadjuvant chemotherapy plus concurrent chemotherapy and high-dose radiation for squamous cell carcinoma of the esophagus: a preliminary 
analysis of the phase II intergroup trial 0122. Journal of clinical oncology : official journal of the American Society of Clinical Oncology 1996;14(1):149-55.

10. Ajani JA, Winter $\mathrm{K}$, Komaki R, et al. Phase II randomized trial of two nonoperative regimens of induction chemotherapy followed by chemoradiation in patients with localized carcinoma of the esophagus: RTOG 0113. Journal of clinical oncology : official journal of the American Society of Clinical Oncology 2008;26(28):4551-6.

11. Mason KA, Hunter NR, Milas M, Abbruzzese JL, Milas L. Docetaxel enhances tumor radioresponse in vivo. Clinical cancer research : an official journal of the American Association for Cancer Research 1997;3(12 Pt 1):2431-8.

12. Hennequin $C$, Giocanti N, Favaudon V. Interaction of ionizing radiation with paclitaxel (Taxol) and docetaxel (Taxotere) in HeLa and SQ20B cells. Cancer research 1996;56(8):1842-50.

13. Zhang $\mathrm{P}, \mathrm{Xi} \mathrm{M}, \mathrm{Li} \mathrm{OQ}$ et al. Concurrent cisplatin and 5-fluorouracil versus concurrent cisplatin and docetaxel with radiotherapy for esophageal squamous cell carcinoma: a propensity score-matched analysis. Oncotarget 2016.

14. Zhao $\mathrm{T}$, Chen $\mathrm{H}$, Zhang $\mathrm{T}$. Docetaxel and cisplatin concurrent with radiotherapy versus 5-fluorouracil and cisplatin concurrent with radiotherapy in treatment for locally advanced oesophageal squamous cell carcinoma: a randomized clinical study. Medical oncology 2012;29(5):3017-23.

15. Li QQ, Liu MZ, Hu YH, Liu H, He ZY, Lin HX. Definitive concomitant chemoradiotherapy with docetaxel and cisplatin in squamous esophageal carcinoma. Diseases of the esophagus : official journal of the International Society for Diseases of the Esophagus / I.S.D.E 2010;23(3):253-9.

16. Hihara J, Yoshida K, Hamai Y, Emi M, Yamaguchi Y, Wadasaki K. Phase I study of docetaxel (TXT) and 5-fluorouracil (5-FU) with concurrent radiotherapy in patients with advanced esophageal cancer. Anticancer research 2007;27(4C):2597-603.

17. Einzig AI, Neuberg D, Remick SC, et al. Phase II trial of docetaxel (Taxotere) in patients with adenocarcinoma of the upper gastrointestinal tract previously untreated with cytotoxic chemotherapy: the Eastern Cooperative Oncology Group (ECOG) results of protocol E1293. Medical oncology 1996;13(2):87-93.

18. Choy $\mathrm{H}$. Combining taxanes with radiation for solid tumors. International journal of cancer 2000;90(3):113-27.

19. Ishida K, Ando N, Yamamoto S, Ide H, Shinoda M. Phase II study of cisplatin and 5-fluorouracil with concurrent radiotherapy in advanced squamous cell carcinoma of the esophagus: a Japan Esophageal Oncology Group (JEOG)/Japan Clinical Oncology Group trial (JCOG9516). Japanese journal of clinical oncology 2004;34(10):615-9.

20. Ohtsu A, Boku N, Muro K, et al. Definitive chemoradiotherapy for T4 and/or M1 lymph node squamous cell carcinoma of the esophagus. Journal of clinical oncology : official journal of the American Society of Clinical Oncology 1999;17(9):2915-21

21. Minsky BD, Neuberg D, Kelsen DP, et al. Final report of Intergroup Trial 0122 (ECOG PE-289, RTOG 90-12): Phase II trial of neoadjuvant chemotherapy plus concurrent chemotherapy and high-dose radiation for squamous cell carcinoma of the esophagus. International journal of radiation oncology, biology, physics 1999;43(3):517-23.

22. Chandra A, Guerrero TM, Liu HH, et al. Feasibility of using intensity-modulated radiotherapy to improve lung sparing in treatment planning for distal esophageal cancer. Radiotherapy and oncology : journal of the European Society for Therapeutic Radiology and Oncology 2005;77(3):247-53.

23. Wu VW, Kwong DL, Sham JS. Target dose conformity in 3-dimensional conformal radiotherapy and intensity modulated radiotherapy. Radiotherapy and oncology : journal of the European Society for Therapeutic Radiology and Oncology 2004;71(2):201-6.

24. Wu Q, Manning M, Schmidt-Ullrich R, Mohan R. The potential for sparing of parotids and escalation of biologically effective dose with intensity-modulated radiation treatments of head and neck cancers: a treatment design study. International journal of radiation oncology, biology, physics 2000;46(1):195-205.

25. Katsumata N, Yasuda M, Takahashi F, et al. Dose-dense paclitaxel once a week in combination with carboplatin every 3 weeks for advanced ovarian cancer: a phase 3, open-label, randomised controlled trial. Lancet 2009;374(9698):1331-8.

26. Safra T, Menczer J, Bernstein RM, et al. Combined weekly carboplatin and paclitaxel as primary treatment of advanced epithelial ovarian carcinoma. Gynecologic oncology 2009;114(2):215-8.

27. Yokoyama Y, Takano T, Nakahara K, et al. A phase II multicenter trial of concurrent chemoradiotherapy with weekly nedaplatin in advanced uterine cervical carcinoma: Tohoku Gynecologic Cancer Unit Study. Oncology reports 2008;19(6):1551-6.

28. Sehouli J, Stengel D, Mustea A, et al. Weekly paclitaxel and carboplatin (PC-W) for patients with primary advanced ovarian cancer: results of a multicenter phase-II study of the NOGGO. Cancer chemotherapy and pharmacology 2008;61(2):243-50.

29. Hasegawa Y, Takanashi S, Okudera K, et al. Weekly paclitaxel and nedaplatin with concurrent radiotherapy for locally advanced non-small-cell lung cancer: a phase I/II study. Japanese journal of clinical oncology 2004;34(11):647-53.

30. Yuan G, Wu L, Huang M, Li N, An J. A phase II study of concurrent chemo-radiotherapy with weekly nedaplatin in advanced squamous cell carcinoma of the uterine cervix. Radiation oncology 2014;9:55.

31. Hamada Y, Naitoh H, Niibe $Y$, et al. Initial analysis of relationship between plasma platinum concentration and hematological adverse reaction associated with weekly chemotherapy using nedaplatin in combination with radiotherapy for cervical carcinoma. European journal of gynaecological oncology 2010;31(5):517-21.

32. Gascon P, Aapro M, Ludwig H, et al. Treatment patterns and outcomes in the prophylaxis of chemotherapy-induced (febrile) neutropenia with biosimilar filgrastim (the MONITOR-GCSF study). Supportive care in cancer : official journal of the Multinational Association of Supportive Care in Cancer 2016;24(2):911-25.

33. Aapro MS, Bohlius J, Cameron DA, et al. 2010 update of EORTC guidelines for the use of granulocyte-colony stimulating factor to reduce the incidence of chemotherapy-induced febrile neutropenia in adult patients with lymphoproliferative disorders and solid tumours. European journal of cancer 2011;47(1):8-32.

34. Aapro MS, Cameron DA, Pettengell R, et al. EORTC guidelines for the use of granulocyte-colony stimulating factor to reduce the incidence of chemotherapy-induced febrile neutropenia in adult patients with lymphomas and solid tumours. European journal of cancer 2006;42(15):2433-53. 